UCRL-JC-128090

PREPRINT

\title{
Loss of Transmittance in Fluoropolymer Films due to Laser-Induced Damage at 1053 and 351-nm
}

\author{
P. Whitman \\ D. Milam \\ M. Norton \\ W. Sell
}

This paper was prepared for and presented at the 29th Annual Symposium on Optical Materials for High Power Lasers

Boulder, Colorado

October 6-8, 1997

December 1, 1997

This is a preprint of a paper intended for publication in a journal or proceedings. Since changes may be made before publication, this preprint is made available with the understanding that it will not be cited or reproduced without the permission of the author. 


\section{DISCLAIMER}

This document was prepared as an account of work sponsored by an agency of the United States Government. Neither the United States Government nor the University of California nor any of their employees, makes any warranty, express or implied, or assumes any legal liability or responsibility for the accuracy, completeness, or usefulness of any information, apparatus, product, or process disclosed, or represents that its use would not infringe privately owned rights. Reference herein to any specific commercial product, process, or service by trade name, trademark, manufacturer, or otherwise, does not necessarily constitute or imply its endorsement, recommendation, or favoring by the United States Government or the University of California. The views and opinions of authors expressed herein do not necessarily state or reflect those of the United States Government or the University of California, and shall not be used for advertising or product endorsement purposes. 


\title{
Loss of transmittance in fluoropolymer films due to laser- induced damage at 1053 and $351-\mathrm{nm}$
}

\author{
P. Whitman, D. Milam, M. Norton, W. Sell \\ Lawrence Livermore National Laboratory \\ P.O. Box 5508, L-487 \\ Livermore, CA 94551-9900
}

\begin{abstract}
Thick fluoropolymer films are being evaluated as a potential 'disposable' debris shield to protect high-peak-power laser optics from x-ray and target debris generated in inertial-confinement fusion-ignition experiments. Two obstacles to implementation are optical uniformity and damage threshold. To understand the damage characteristics, transmittance of singlc 1053- or 351-nm laser pulses has bcen measured for commercial fluoropolymer films in vacuum. Samples were tested at fluences up to $105 \mathrm{~J} / \mathrm{cm} 2$ at $1053-\mathrm{nm}$ and $13 \mathrm{~J} / \mathrm{cm} 2$ at $351-\mathrm{nm}$. Both the total transmitted energy for a single shot and the temporal energy transmittance profile during the shot were measured as a function of fluence. In addition, the total focusable transmitted energy was recorded for 351-nm pulses.
\end{abstract}

Results show that transmittance decreases slowly during a single-pulse irradiation, allowing much of the energy to be transmitted at fluences which cause noticeable degradation to the film. The film transmits greater than $90 \%$ of the $351-\mathrm{nm}$ energy delivered in a beam with spatial average fluence of $8 \mathrm{~J} / \mathrm{cm} 2$ with modulation up to $15 \mathrm{~J} / \mathrm{cm} 2$. For $1053-\mathrm{nm}$ laser light, the films do not begin to exhibit noticeable transmittance loss until average fluences exceed $40 \mathrm{~J} / \mathrm{cm} 2$.

Keywords: fluoropolymer, FEP, laser damage, inertial confinement fusion

\section{INTRODUCTION}

The heart of the National Ignition Facility (NIF), a U.S. Department of Energy national center for the study of inertialconfinement fusion and high-energy-density science, is an extremely powerful solid-state laser consisting of 192 separate beams which will collectively produce a peak power of about $500 \mathrm{TW}$. This laser will focus $1.8 \mathrm{MJ}$ of $351-\mathrm{nm}$ laser light onto a fusion target, which will then emit $220-\mathrm{eV}$ blackbody $\mathrm{x}$-rays, $14-\mathrm{MeV}$ neutrons, ions and shrapnel. In addition, approximately $1 \mathrm{MJ}$ of residual unconverted 1053-nm light, and a small amount of partially converted 525-nm light and scattered 351$\mathrm{nm}$ light will be diverted from the target and irradiate the target chamber wall. The final optic in the laser chain, known as the 'debris shield,' is the interface between this hostile target chamber environment and the more expensive focus lens.

Fig. 1 shows a fused silica Nova debris shield at the end of its useful life. Nova, is a member of the current generation of high-power-solidstate lasers and is capable of focusing up to $30 \mathrm{KJ}$ of $351-\mathrm{nm}$ light on a fusion target. The observed damage on the Nova debris shield is the cumulative effect of 6 months of laser and impact damage attributable to target debris and contamination. For NIF, modeling ${ }^{\prime}$ has predicted that a single $1.8 \mathrm{MJ}$ shot producing $100 \mathrm{KJ}$ of fusion encrgy (the maximum design fluence) will generate up to $1 \mathrm{~J} / \mathrm{cm}^{2}$ of $\mathrm{x}$-ray at the debris shield as well as hurl nearly a million liquid projectiles at velocities up to $10 \mathrm{~km} / \mathrm{sec}$ and tens or hundreds of larger solid shrapnel at lower velocity. Yet, this debris shield will be expected to survive multiple exposures to high fluence $351-\mathrm{nm}$ shots up to 8 $\mathrm{J} / \mathrm{cm}^{2}$ avg, $12 \mathrm{~J} / \mathrm{cm}^{2}$ peak, $3-\mathrm{ns}$ before refurbishment is required.

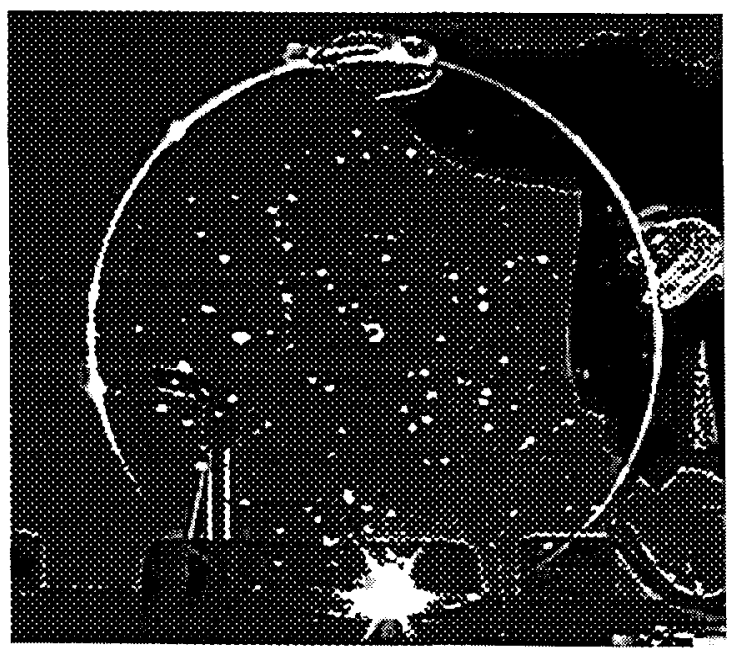

Fig. 1 A $65 \mathrm{~cm}$ fused silica Nova debris shield at the end of its useful life. 


\section{OBJECTIVE}

The objective of this work is to find an inexpensive, single usage or sacrificial optic to prolong the useful life of the fused silica debris shield. Fig. 2 depicts the placement of this thin optical film between the target and the debris shield. The thin film would absorb the x-ray fluence and prevent all but the largest and highest velocity liquid splats from reaching the fused silica debris shield.

Teflon films are one material being considered for use as a 'single shot disposable debris shield'. These films have previously been shown to survive high fluences, in the sense that the material is not destroyed after a single shot nor by $x$-ray fluences up $1 \mathrm{~J} / \mathrm{cm} 2$. But after the shot a bcam footprint is apparent as a cloudy area. Thus these tests were proposed to give

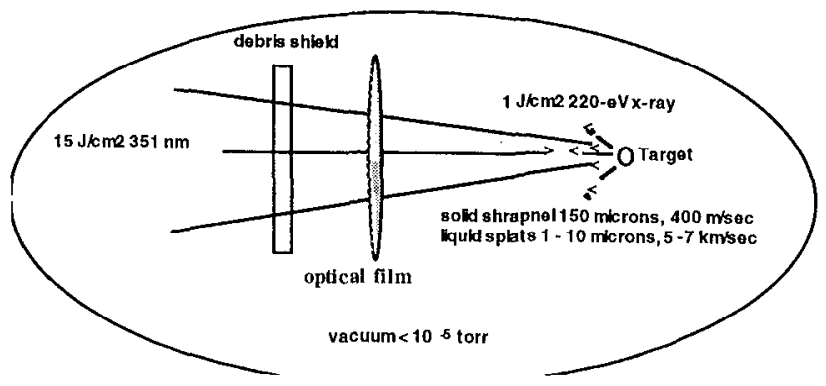

Fig. 2 The debris shield is the interface between the laser optics and the target chamber a first look at 1 and $3 \omega$ transmittance during the entire pulse width. The assumption that the laser pulse actually got through before the cloudiness occurred was to be tested.

Three different DuPont fluoropolymer films were tested: FEP100A, TEDLAR PVF, and an experimental material made from a solution castable tetrafluorethylene-hexafluorpropene copolymer. FEP100A is a $25 \mu \mathrm{m}$ thick commercial film comprised of hexafluoropropene - tetrafluoroethylene copolymer. TEDLAR PVF is a commercial polyvinyl fluoride film.

\section{PERFORMANCE AT 1053 NM}

\subsection{Experimental conditions}

The experimental layout is shown schematically in Fig. 3. The source was a high average power glass slab laser used in single shot mode. Laser energies from 1 to $15 \mathrm{~J}$ at $1053-\mathrm{nm}$, with FWHM $\sim 16 \mathrm{nsec}$ and a beam area at the Teflon of $\sim 0.12 \mathrm{~cm}^{2}$ were employed. The Teflon films were mounted in a slide holder and positioned in an $x-y$ translation stage located within a vacuum chamber. A vacuum in the $10^{-4}$ to $10^{-5}$ torr range was maintained for all shots. Vacuum mechanical rotating feed throughs allowed as many as 9 fresh spots on the film to be exposed beforc the vacuum was broken to install a new slide.

The slide was positioned in the near ficld of a $f / 16$ lens. The transmitted beam was recollimated and a sample of the beam was scnt to the diagnostics.

Input energy and output energies were measured with calibrated joulcmeters. Input temporal wave shapes were measured with a vacuum photodiode. Output wave shapes were measured with a fast silicon diode. $\Lambda$ fast digital scope, $1 \mathrm{GHz}$ bandwidth, was used to record the waveforms. Measurement accuracy of the energy is good to about $10 \%$. Waveforms are shown in units of $\mathrm{MW} / \mathrm{cm}^{2}$; the required scaling factor was obtained from either the input or output energy meters as appropriate during calibration shots without the Teflon in the chamber. These scaling factors were then used for all transmitted and input waveforms No other scaling was used to overlay the pulses except a translation in time to account for the time delay between input and output

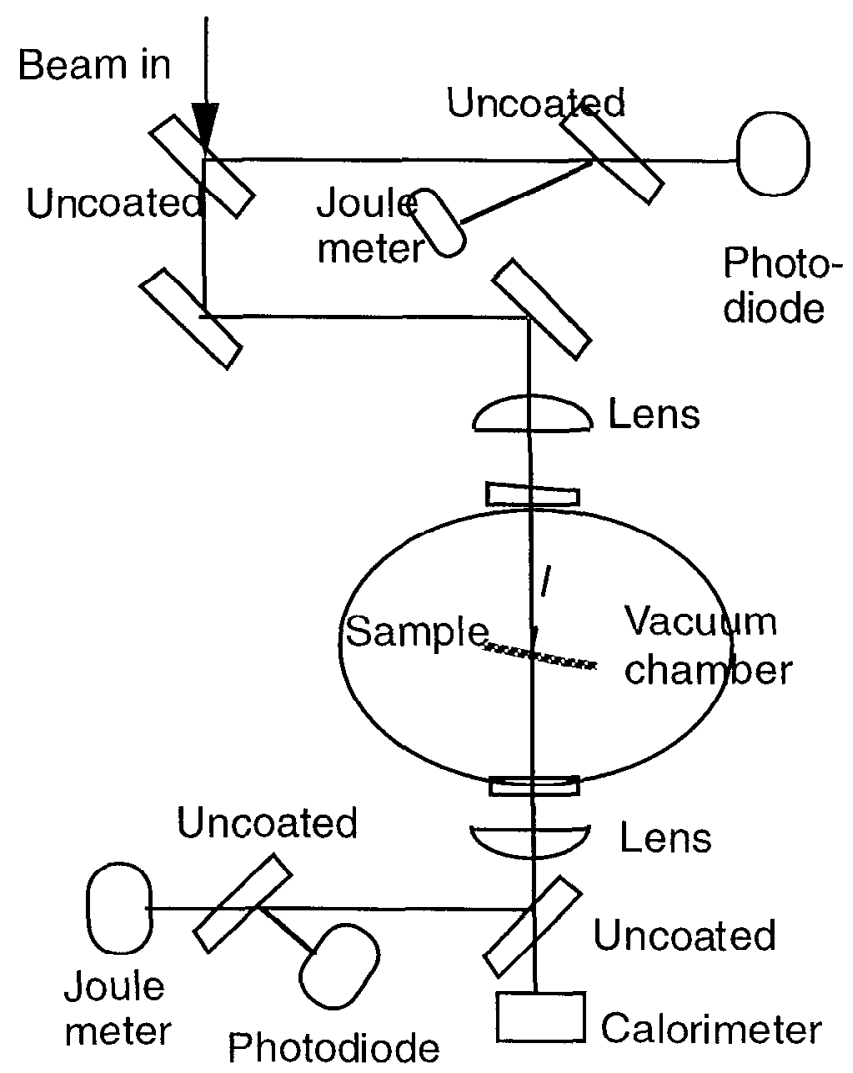

Fig. 3 Experimental setup for 1053-nm laser light 
delay between input and output pulses. No accounting has been made for the expected Fresnel losses; thus the maximum transmittance expected is less than 1 . Based on spectrophotometry of very thin films of these materials, the expected surface reflection losses are $4.5 \%$ at $1 \mu \mathrm{m}$ (consistent with a refractive index of 1.35).

Future measurements would preferably done with a vacuum photodiode for both the output and input pulses. At this point we attribute some of the subtle and not so subtle differences in input and output waveform shapes to using two different detectors. Though the silicon photodiode used for the output utilizes a lens/diffuser combination to get nearly a full beam area sample of the beam onto the very small silicon diode this arrangement is not as effective as putting the entire cross section onto the detector as is possible with the large area Hamamatsu vacuum photodiode used for the input.

\subsection{Results}

For FEP100A the fluence was varied from $8 \mathrm{~J} / \mathrm{cm}^{2}$ to $105 \mathrm{~J} / \mathrm{cm}^{2}$. From 8 to $30 \mathrm{~J} / \mathrm{cm}^{2}$ the transmitted waveform follows the input wave form and there is no significant loss in transmitted energy. Some of the recorded waveforms in this fluence range are shown in Fig. 4. Somewhere between 50 and $75 \mathrm{~J} / \mathrm{cm}^{2}$ the pulse noticeably begins to cut off the tail, which can be seen in Fig. $4 \mathrm{c}$ at $74 \mathrm{~J} / \mathrm{cm}^{2}$. There is a concurrent loss of $12 \%$ in the transmitted energy. By $105 \mathrm{~J} / \mathrm{cm}^{2}$ the cutoff of the tail is very pronounced as is shown in Fig. $4 \mathrm{~d}$ Now the transmitted energy is only $66 \%$.
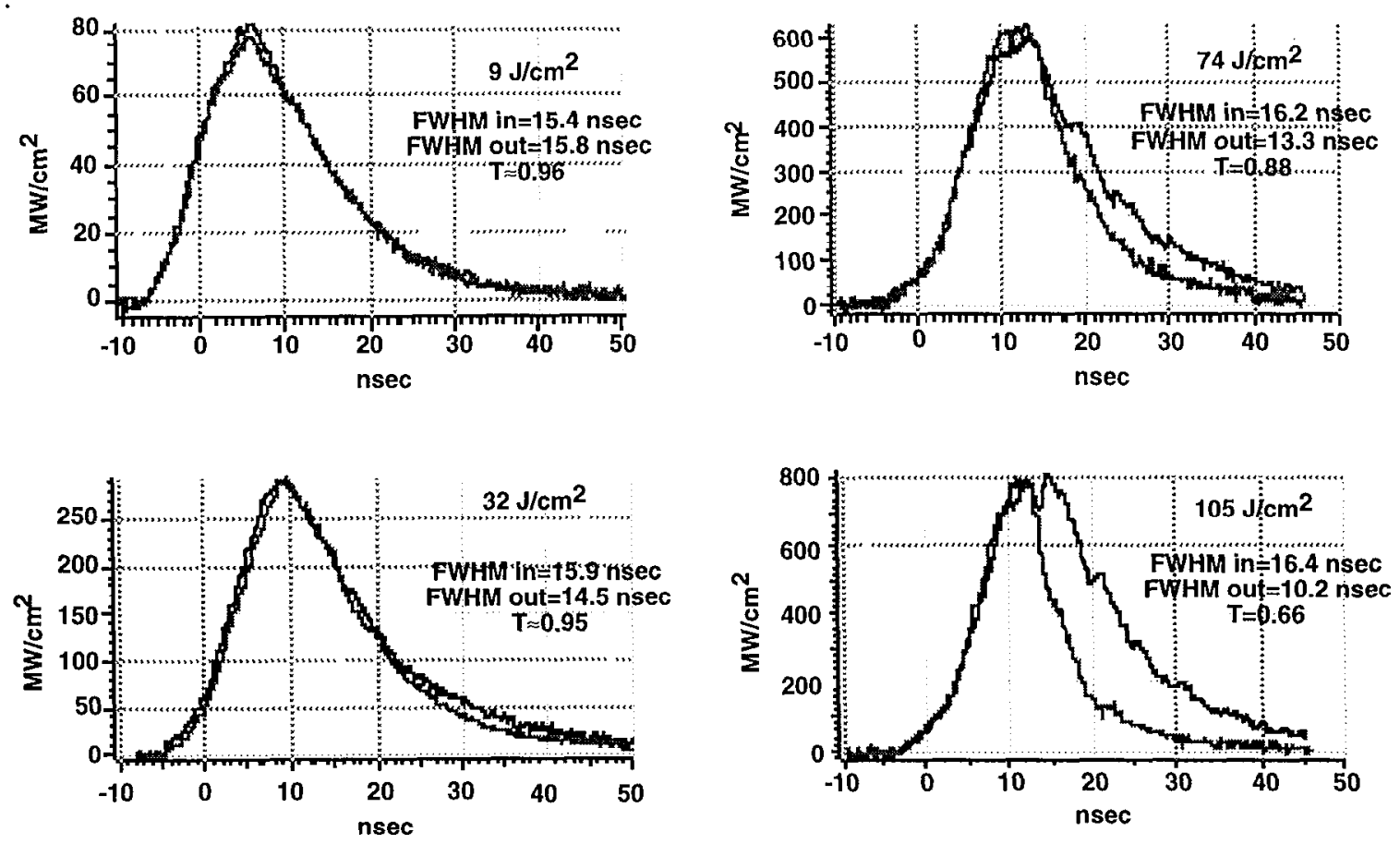

Fig. 4 Representative waveforms for FEP100A at 1053-nm: a) $9 \mathrm{~J} / \mathrm{cm} 2$, b) $32 \mathrm{~J} / \mathrm{cm} 2$, c) $74 \mathrm{~J} / \mathrm{cm} 2$ and d) $105 \mathrm{~J} / \mathrm{cm} 2$. Black traces are the input waveforms and grey traces are the output.

The experimental fluoropolymer does not perform as well as the FEP100A. At $30 \mathrm{~J} / \mathrm{cm}^{2}$ transmittance has dropped to about $80 \%$ as compared to the FEP which is still transmitting without loss within our measurement accuracy. At $58 \mathrm{~J} / \mathrm{cm}^{2}$ less than $60 \%$ of the pulse is transmitted. At $100 \mathrm{~J} / \mathrm{cm}^{2}$ only $40 \%$ gets through compared to $66 \%$ for the FEP and a hole the size of the beam footprint was produced. The shape of some of these pulses are shown in Fig. 5 .

Tedlar was only tested up to $36 \mathrm{~J} / \mathrm{cm}^{2}$ where it transmitted just under $80 \%$. Its properties might be comparable to the experimental fluoropolymer but not enough data were taken with this material. A few waveforms can be seen in Fig. 5

The scattering footprints which develop in the FEP film after a single shot at fluences from 32 to $105 \mathrm{~J} / \mathrm{cm} 2$ are shown in Fig. 6. Although a strong footprint develops after exposure to $49 \mathrm{~J} / \mathrm{cm} 2$, we did not detect a significant loss of transmittance during the shot.

Fig. 7 compiles the 1 micron transmittance as a function of fluence for all materials and test runs The slope of these curves is quite similar for all three materials, however the onset of significant transmittance loss is delayed until around $50 \mathrm{~J} / \mathrm{cm} 2$ for the best material, the FEP. 

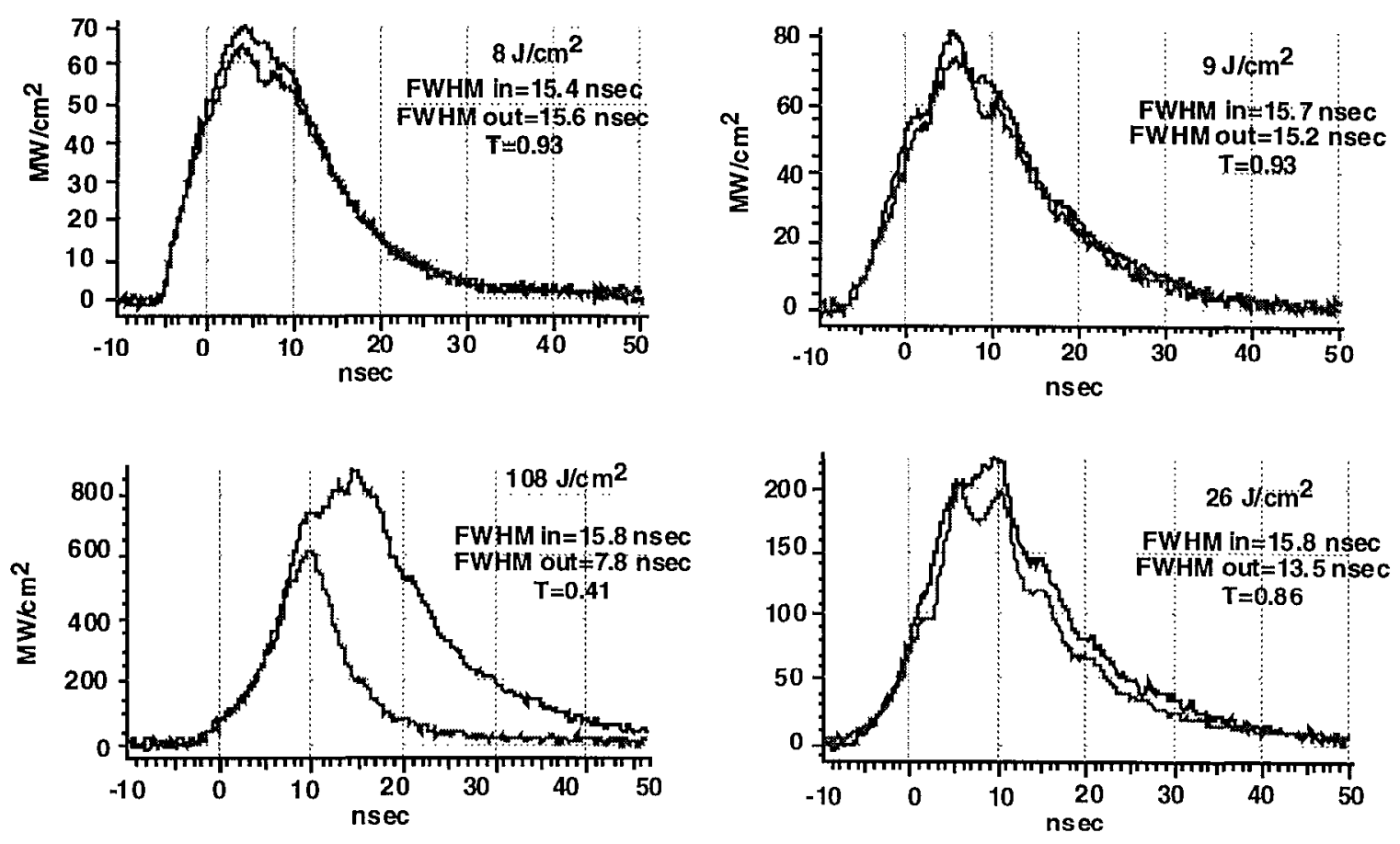

\section{Exp'l HFP/TFE}

Tedlar PVF

Fig. 5 Representative 1053-nm waveforms for the experimental fluoropolymer a) $8 \mathrm{~J} / \mathrm{cm} 2$ and b) $108 \mathrm{~J} / \mathrm{cm} 2$, and Tedlar c) $9 \mathrm{~J} / \mathrm{cm} 2$ and d) $26 \mathrm{~J} / \mathrm{cm} 2$. Black traces are the input waveforms and grey traces are the output.

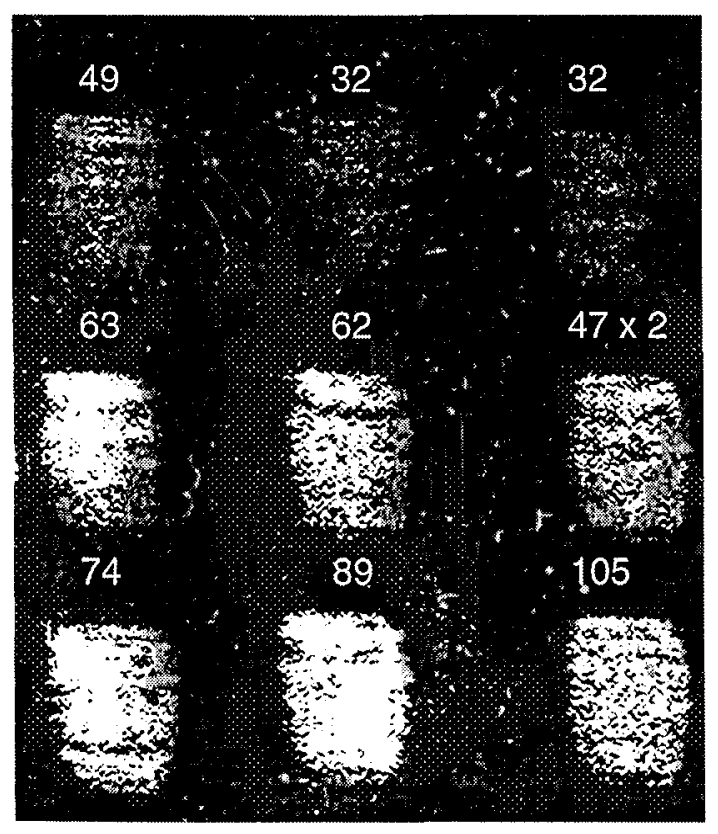

Fig. 6 FEP 100A Beam footprints after exposure to 1053-nm, 17-nsec pulse. Shot fluence is indicated above the footprint in $\mathrm{J} / \mathrm{cm}^{2}$

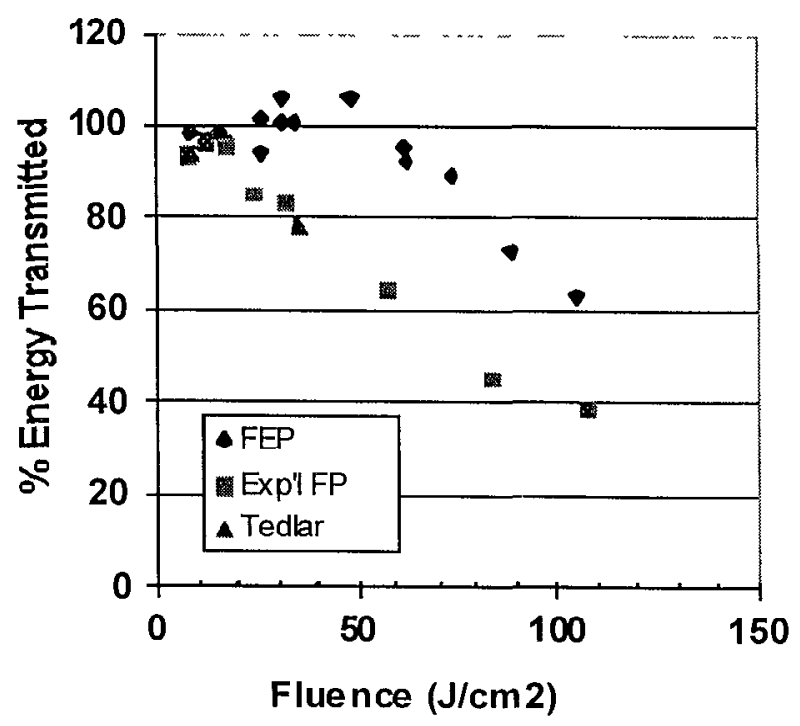

Fig. 7 Transmittance degradation as a function of fluence at $1053-\mathrm{nm}$ for three teflon polymer films 


\section{PERFORMANCE AT 351-nm}

\subsection{Experimental conditions}

The arrangement for the 351-nm experiment is shown in Fig. 8. All of the samples were virgin (as received) commercially available FEP films, except for one that had been heated to $350{ }^{\circ} \mathrm{C}$ for 30 minutes prior to exposure. The samples were mounted in a vacuum chamber that was evacuated to a pressure of $10^{-5}$ Torr.

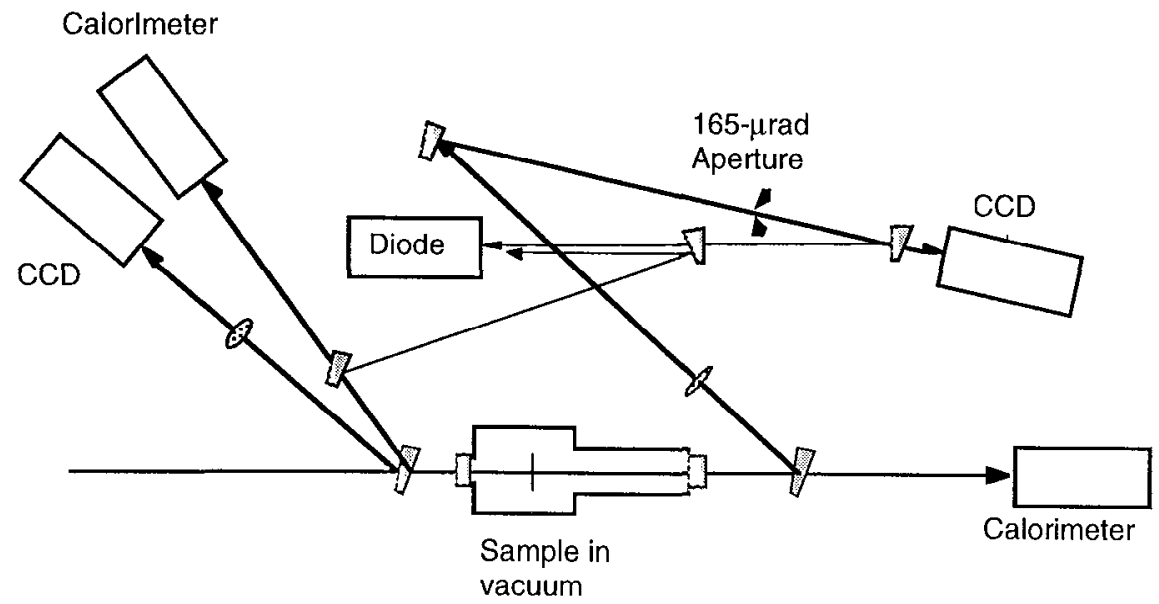

Fig. 8 Experimental setup for measuring transmittance of $351 \mathrm{~nm}$ laser light through FEP100A fluoropolymer

The input 351-nm pulse was $6.5 \mathrm{~ns}$ in duration, and the diameter of the beam at the sample was $7.5 \mathrm{~mm}$. A calorimeter and a CCD camera were used to measure the energy of the input pulse, and the spatial distribution of its fluence. A second calorimeter with collection angle of several mrad was positioned at the output of the chamber, and used to measure the total transmitted energy. A fraction of the output beam was focused through an aperture with diameter of $0.75 \mathrm{~mm}$ by a lens with focal length of $2.27 \mathrm{~m}$, and sent to a photodiode. The angular acceptance of the aperture was $165 \mathrm{mrad}$ (half angle), which is about 3 times the diffraction limit for a $7.5-\mathrm{mm}$ beam. The waveform of the incident pulse was recorded by the same diode. The function of this apertured arrangement was to observe loss due to induced scattering, which might not be registered by the output calorimeter.

Fluence in the inpul beam was spatially modulated. It varied by about a factor of 2 , which is not unlike the variation that is predicted for beams in the NIF. A histogram of the beam fluences for each shot was generated, and the median of the distribution was defined to be the averaged fluence. Histograms of the shots arc shown in Fig.9.

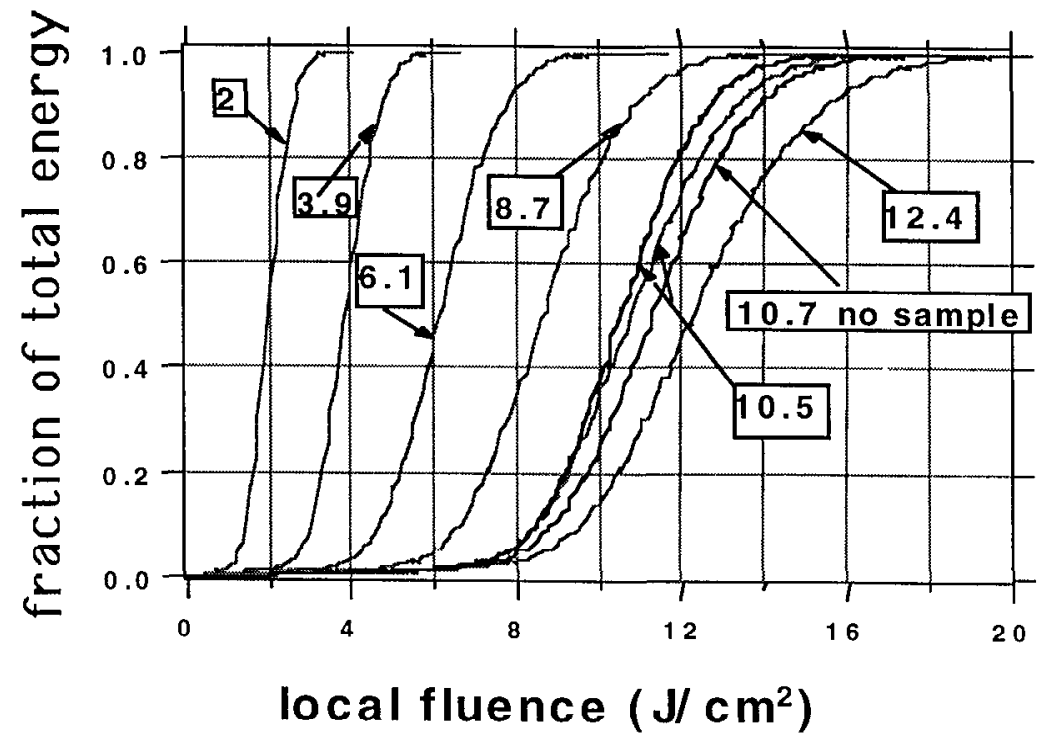

Fig. 9 Histograms of the spatial distribution of the input beam fluence for 351-nm pulses. The numerical values indicate the reported average in $\mathrm{J} / \mathrm{cm}^{2}$. 
Randomly selected sites on the sample were subjected to a single irradiation at spatially averaged input fluences ranging from 2 to $15 \mathrm{~J} / \mathrm{cm}^{2}$. Some of the recorded waveforms are shown in Fig. 10. The input and output waveforms were normalized to have value unity at the onset of each pulse, and relative energies were calculated by integrating the waveforms. Shot-by shot normalization was necessary because the optical nonuniformity of the sample caused a site-to-site variation of the transmittance through the aperture.
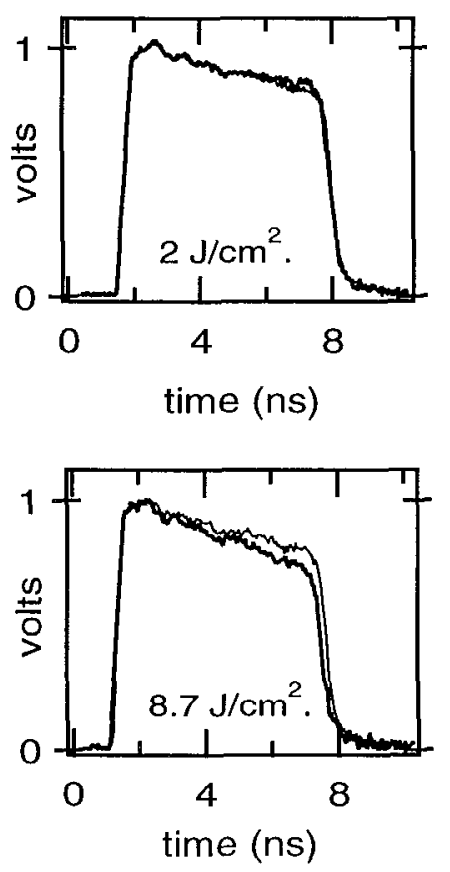
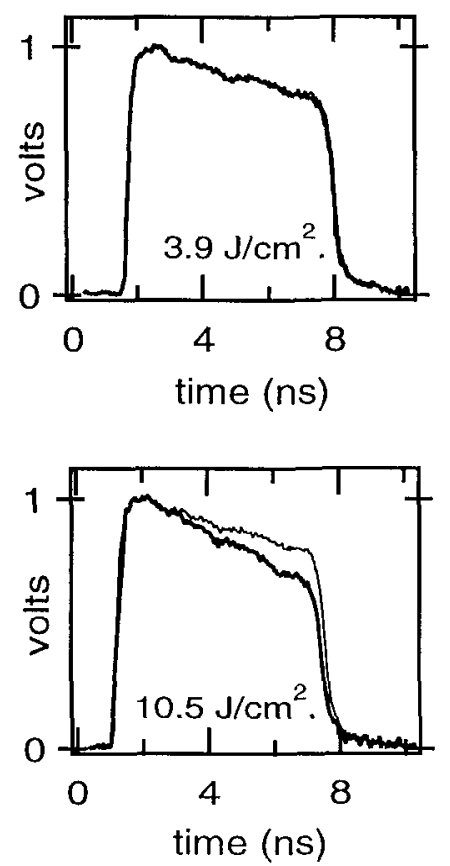
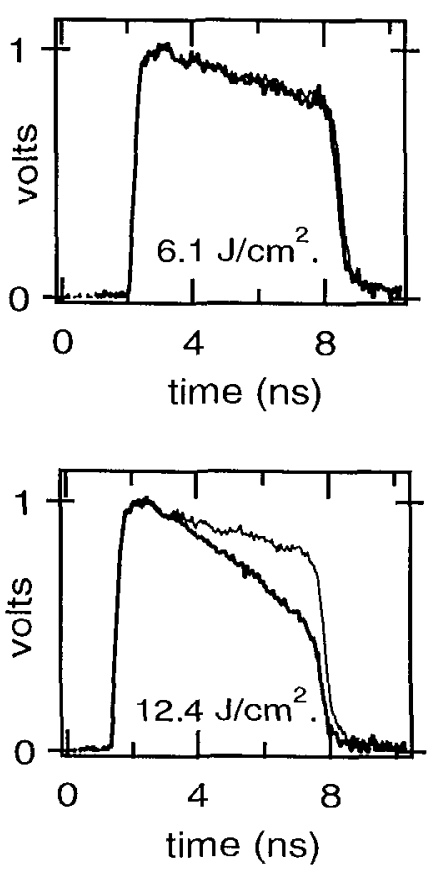

Fig. 10 Pinhole transmittance input (fine) and output (bold) waveforms as a function of average 351-nm fluence.

A summary of the apertured measurements is given in Fig. 11 . For fluences of $2-6 \mathrm{~J} / \mathrm{cm}^{2}$, the transmittance through the aperture was constant to within experimental uncertainty of about $2 \%$. At fluence of $8.7 \mathrm{~J} / \mathrm{cm}^{2}$, which approximated the NIF maximum operating fluence, there was a loss of about $5 \%$ in the transmitted energy, and at the end of the pulse, a power loss of about $10 \%$. At $15 \mathrm{~J} / \mathrm{cm}^{2}$, the film did not survive intact; a cleanly edged hole the size of the bcam was excised. Fig. 12 shows the scattering footprints which develop in the FEP film after a single shot at fluences from 3 to $10 \mathrm{~J} / \mathrm{cm}^{2}$.

Fig. 11 also contains the transmittances that were measured by the ratio of input and output calorimetry. Because the calorimetric measurements are ratios of absolute measurements of energy, they include the transmittance of the AR-coated chamber windows and the film. The calorimetrically measured transmittance was about $93.5 \%$ at low power, and about $91 \%$ for the shot at $8.7 \mathrm{~J} / \mathrm{cm}^{2}$. The fractional loss, about $3 \%$, was slightly less than that measured by the comparison of waveforms.

Fig. 11 also contains the results of the single irradiation of the film that had been baked at $350 \mathrm{C}$. Both measurements indicated a transmittance of about $83 \%$.

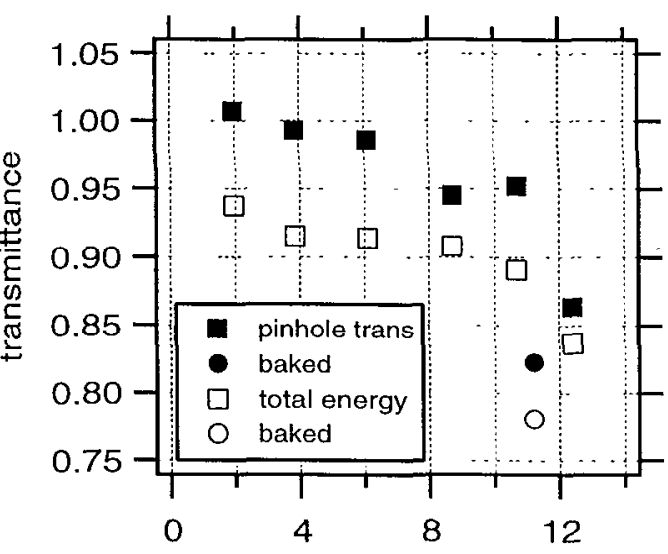

$351-\mathrm{nm}$ fluence $(\mathrm{J} / \mathrm{cm} 2)$

Fig. 11 Pinhole transmittance (solid symbols) and calorimctrically mcaused (open symbols) transmittancc of FEP films as a function of $351-\mathrm{nm}$ fluence 


\section{SUMMARY}

These experiments show the potential for transmitting 1 micron laser light with little loss through FEP100A up to 30$50 \mathrm{~J} / \mathrm{cm}^{2}$ and for transmitting $351-\mathrm{nm}$ lascr light with littlc loss up to $10 \mathrm{~J} / \mathrm{cm} 2$. The FEP100A clearly outperforms the two other materials tested. It is remarkably robust. The demonstrated behavior at 1053 and $351-\mathrm{nm}$ is consistent with utilizing this material as a disposable debris shield for NIF.

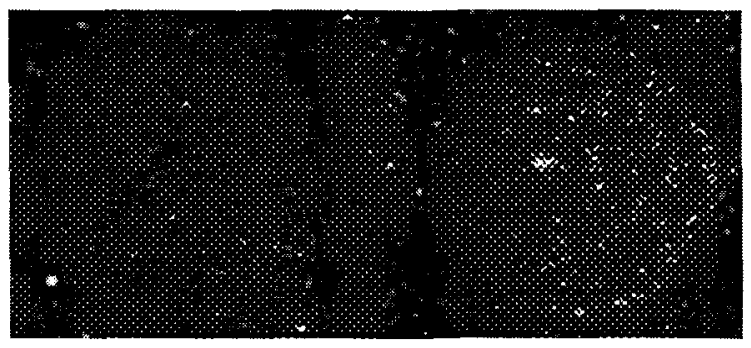

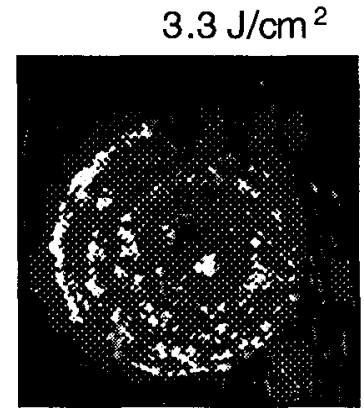

$7.3 \mathrm{~J} / \mathrm{cm}^{2}$
$6.5 \mathrm{~J} / \mathrm{cm}^{2}$

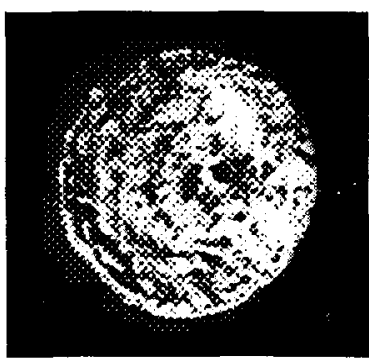

$9.8 \mathrm{~J} / \mathrm{cm}^{2}$

Fig. 12 Beam footprints in FEP100A film after exposure to 351-nm fluence.

\section{ACKNOWLEDGEMENTS}

This work was performed under the auspices of the US Department of Encrgy by Lawrence Livermore National Laboratory under contract No. W-7405-Eng-48.

\section{REFERENCES}

1. R. Tokheim, L. Seaman, L. Cooper, T. Lew, D. Curran, J. Sanches, A. Anderson, M. Tobin, "Calculating the shrapnel generation and subsequent damage to first wall and optics components for the National Ignition Facility," Fusion Tech, V30(N3 PT2A), pp. 745-51, December, 1996.

2. F. Rainer, A. Anderson, A. Burnham, D. Milam, R. Turner, "Lifetime survivability of contaminated target-chamber optics", Laser-Induced Damage in Optical Materials: 1996, SPIE Vol 2966, pp. 463- 73, October, 1996. 


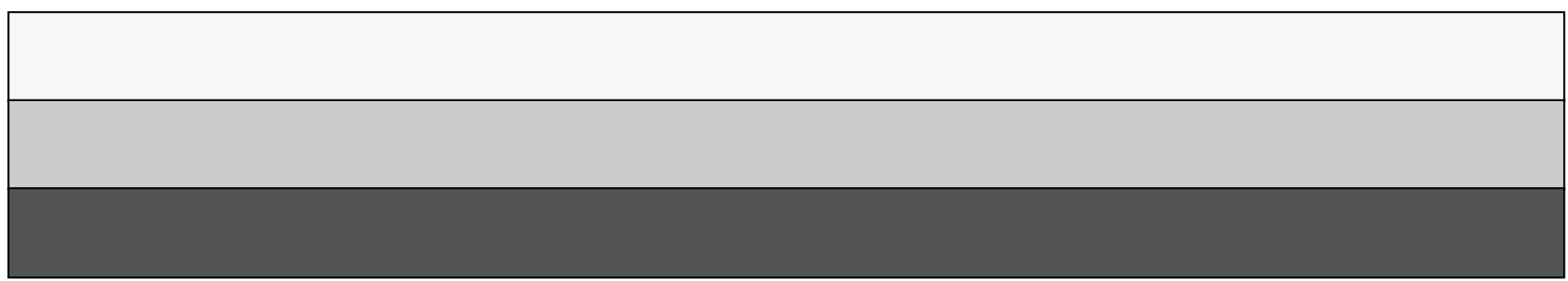

